(c) 2010 IEEE. Personal use of this material is permitted. Permission from IEEE must be obtained for all other uses, in any current or future media, including reprinting/republishing this material for advertising or promotional purposes, creating new collective works, for resale or redistribution to servers or lists, or reuse of any copyrighted component of this work in other works. 


\title{
Conceptual SLA Framework for Cloud Computing
}

\author{
Mohammed Alhamad, Tharam Dillon, Elizabeth Chang \\ Digital Ecosystems and Business Intelligence Institute (DEBII) \\ Curtin University of Technology \\ Perth, Australia \\ Mohammed.Alhamad@postgrad.curtin.edu.au, \\ Tharam.Dillon@cbs.curtin.edu.au, Elizabeth.Chang@cbs.curtin.edu.au
}

\begin{abstract}
Cloud computing has been a hot topic in the research community since 2007 . In cloud computing the online services are conducted to be pay as you use. Services need not to be in a long term contract with service providers. Service level agreements (SLAs) are agreements signed between a service provider and other party like a service consumer, broker agent, or monitoring agent. Because cloud computing is recent technology providing many services for critical business applications, the need for reliable and flexible mechanisms to manage online contracts is very important. This paper presents the main criteria which should be considered at the stage of designing SLA in cloud computing. Also, we investigate the negotiation strategies between cloud provider and cloud consumer and propose our method to maintain the trust and reliability between each party which is involved in the negotiation processes.
\end{abstract}

Index Terms: SLA, Negotiation, Cloud computing, Trust management

\section{Introduction}

Cloud computing has been a hot topic in the research community recently. In cloud computing the online services are conducted as pay as you use. It is not necessary to be in a long term contract with service providers [1]. In this case, cloud customers can save large amounts of budget that spending to operate, manage and transfer services. Cloud computing can be described as a new form of IT environment which provides dynamic, flexible and scalable virtualization of resources. Examples today for cloud providers are: Amazon EC2 [2] (infrastructure cloud provider), Azure [3] from Microsoft (platform cloud provider), and for an application cloud provider is Google Docs [4] . In cloud computing, virtualization technology is built on the top of the infrastructure in order to optimize the use of resources and provide flexible solutions for users. An important element to provide some degree of assurance to both users and providers of these cloud resources is the use of Service Level Agreements to define the scope of usage and provision of resources. Cloud consumers need an SLA before they do migration of their infrastructure to cloud data centres, to provide certainty in relations in resources provided and reach productivity. Cloud providers need an SLA to define the trust and quality of services they provide to users as well as an agreed charging framework. The research on SLA and QoS metrics has been considered by many researchers in business and service oriented architecture such as e-commerce and web services. However, SLA metrics in these technologies are not suitable for cloud computing as the nature and type of resources being provided and delivered is different. So, new SLA models are still required to provide flexible method for negotiation and signing electronic contracts between consumers and providers. The main contributions of this paper are summarized as follows:

1) Investigating and analysing the main requirements to establish an effective model for SLA in cloud computing

2) Defining dynamic SLA metrics for different group of cloud users

The reminder of this paper is structured as follows: section 2 defines SLAs and describes the main characteristics of SLAs in cloud computing. The existing standards for SLA contracts are presented in section 3. In section 4, properties and main criteria for SLA in cloud computing are described. Also in this section the negotiation model and negotiation senarious for cloud computing are discussed. Section 5 concludes the paper.

\section{Characteristics of Service Level Agreement}

\section{A. Definition}

A Service level agreement is a document that includes a description about agreed service, service level parameters, guarantees, and actions and remedies for all cases of violations [5]. The SLA is very important as a contract between consumer and provider. The main idea of SLAs is to give a clear definition of the formal agreements about service terms like performance, availability and billing. Obligations and the actions for any violation are important to be included 
in the SLA with clearly shared semantics between each party involved in the online contract.

\section{B. Properties of SLAs}

The SLA is a legal format is to how deliver services as well as framework for charging for these services. Service providers use this foundation to optimize their use of infrastructure to meet signed terms of services. Service consumers use the SLA to insure the level of quality of service they need and to maintain acceptable business models for long term provision of services. The following are the main requirements of the SLA:

- SLA format should be able to describe a service in a clear way that the service consumer can easily understand the operation of the services

- Present the level of performance of service

- Define ways as to how the service parameters can be monitored and the format of monitoring reports

- Penalties when service requirements are not meet

- Present the business metrics such as billing and when this service can be terminated without any penalties

This is the requirements for SLAs in the general environment of services. Later, we present the main requirements which the SLA should be implemented to integrate with the cloud computing architecture.

\section{Functional and non-functional requirements for cloud users}

Functional requirements and non-functional requirements of cloud services should be met to fulfil the need of consumers. In this section, classification of cloud computing requirements from the perspective of the cloud consumer is presented helping to provide good understanding of the proposed framework in section 4. For each type of cloud service there are a different requirements. Figure 1 shows the categorization of cloud computing services and requirements for each service.

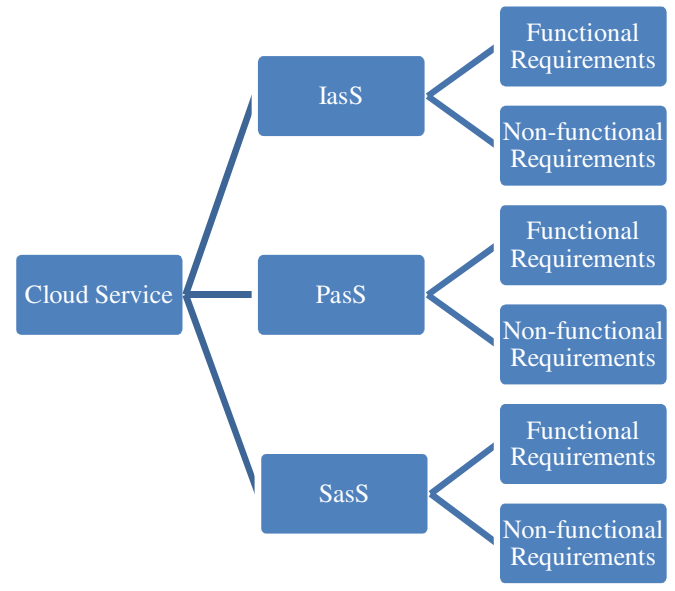

Figure 1. Categorization of requirements for cloud services
In this paper, we focus on the non-functional requirements of services such as availability, scalability and response time. Based on the more important non-functional requirements, we define the SLA parameters for each type of cloud service.

- Availability: in cloud computing the most important criteria for quality of service is the availability of service. Availability is the probability that cloud infrastructure or service are up and running in the specific time of utilities of the service provided for in the SLA

- Scalability: cloud consumers pay for the service only as they use it. The cloud provider should facilitate the specific resources to be easy for scaling up and down. With scalability, cloud consumers can maximize revenue and cloud providers are able to optimize resources effectively.

- A clear method for cost calculation: service consumers using cloud computing are willing to pay as they use, annual billing period or even monthly periods are not suitable for cloud computing. A cost calculation for resource reservation method is not a unique method for each type of cloud services. For example, the storage service can be billed based on the time and size of the user's data. On the other hand, cloud CRM may be billed based on the number of users

- The configuration of service: in cloud computing. Users deal with virtual machines and these VMs should be configured in a flexible manner helping users execute business processes with minimum need for managing effort of the configuration

- $\quad$ Security and privacy: critical data of business must be stored and transferred via secure channels. If security features are not guaranteed by cloud providers, business organizations may spend too much to operate their own data centres rather than switch to cloud providers

\section{SLA Frameworks}

To the best of our knowledge, scientific research in the area of SLA and trust management does not investigate the new paradigm of outsourcing of services in a pay as you use framework, which is called "Cloud Computing". The main specifications which designed to describe the syntax of SLA are: 1) Web Service Agreement (WS-Agreement) [5]. 2) Web Service Level Agreement Language and framework (WSLA) [6]. WS-Agreement created by Open Grid Forum (OGF) in order to create an official contract between service consumers and service providers. This contract should specify the guarantees, the obligations and penalties if there are some violations. Also, the functional requirements and other specification of services can be included in the SLA. There are three main sections for WS-Agreement: name, context, and terms. A unique ID and optional names of services are included in the name section. The information about service consumer and service provider, domain of service, and other 
specification of service is presented in the context section. Terms of services and guarantees are described with more details in the terms section. This type of online agreements were developed to be used with general services. For cloud computing, service consumers lack more specific solutions for SLA to present the main parameters of the visualization environment, and at the same time these solutions should be dynamically integrated with the business rules of cloud consumers. The other specification is WSLA, which was developed to describe services in three categories, which are: 1) Parties: in this section information about service consumers, service providers, and agents are described. 2) SLA parameters: in this section the main parameters which are measurable parameters are presented in two types of metrics. The first is resource metrics, this type of metric is used to describe service provider's resources as row information. The second one is composite metrics. This metrics is used tp represent the calculation of the combination of information about service provider's resources. The final section of the WSAL specification is Service Level Objective (SLO). This section is used to specify the obligations and all actions when service consumers or service providers do not respect the guarantees of services.

The primary shortcoming with these approaches is that they do not provide dynamic negotiation, and various types of cloud consumers need a different structure of implementation of SLAs to integrate their own business rules with the guarantees that are presented in the targeted SLA. In this paper, we propose a basic architecture for developing the service level agreement contract between service consumers and other parties such as service providers and external agents. Two main categories of SLA metrics are presented. Performance metrics that show the measurements of performance parameters in cloud computing data centres such as response time and CPU capacity, the other metrics is business metrics, main measurements of business related aspects will be presented in this type of metrics such as service cost and billing methods.

\section{Conceptual SLA Framework for Cloud Computing}

\section{A. SLA Metrics}

In our proposed framework, the SLA parameters are specified by metrics. These metrics define functions of how cloud service parameters can be measured and specify values of measurable parameters. In the cloud computing architecture, there are four types of services which providers can present to consumers. These services are infrastructure as a service (IasS), platform as a service, software as a service, and storage as a service. Proposed SLA metrics for cloud computing is defined to consider these four types of these services. In each part of SLA we define the most important parameters that consumers can use to create a reliable model of negotiation with this service provider. We focus on the definition of these parameters, in our future work, we will design and implement the proposed framework followed by simulation experiments in order to validate our framework.

\section{SLA metrics for IasS:}

Companies like amazon.com provide infrastructure as a service. Most of the consumers are confused as to which important parameter should be defined in the hardware part of SLA. We list the most important parameters for consumers who are interesting to use cloud as infrastructure service.

Table 1. SLA metrics for IasS

\begin{tabular}{|l|l|}
\hline Parameter & Description \\
\hline CPU capacity & CPU speed for VM \\
\hline Memory size & $\begin{array}{l}\text { Cash memory size for } \\
\text { VM }\end{array}$ \\
\hline Boot time & $\begin{array}{l}\text { Time for MV to be ready } \\
\text { for use }\end{array}$ \\
\hline Storage & $\begin{array}{l}\text { Storage size of data for } \\
\text { short or long term of } \\
\text { contract }\end{array}$ \\
\hline Scale up & $\begin{array}{l}\text { Maximum of VMs for } \\
\text { one user }\end{array}$ \\
\hline Scale down & $\begin{array}{l}\text { Minumum number of } \\
\text { VMs for one user }\end{array}$ \\
\hline Scale up time & $\begin{array}{l}\text { Time to increase a } \\
\text { specific number of VMs }\end{array}$ \\
\hline Scale down time & $\begin{array}{l}\text { Time to decrease a } \\
\text { specific number of VMs }\end{array}$ \\
\hline Auto scaling & $\begin{array}{l}\text { Boolean value for auto } \\
\text { scaling feature }\end{array}$ \\
\hline $\begin{array}{l}\text { Max number can be } \\
\text { configured on physical } \\
\text { server }\end{array}$ & $\begin{array}{l}\text { Maximum number of } \\
\text { VMs that can be run on } \\
\text { individual server }\end{array}$ \\
\hline Availability & $\begin{array}{l}\text { Uptime of service in } \\
\text { specific time }\end{array}$ \\
\hline Response time & $\begin{array}{l}\text { Time to complete and } \\
\text { receive the process }\end{array}$ \\
\hline
\end{tabular}

\section{SLA metrics for PasS:}

Platform as a service is a type of cloud computing that provides all requirements to support application developers for developing, evaluating, and delivering applications and software for end users [7]. So, in this case, developers using PasS do not need to download tools or configure hardware to complete the developing tasks. For SLA metrics related to PasS, we define the main parameters that can be used as basic criteria when developers want to negotiate with PasS providers.

\begin{tabular}{|l|l|}
\multicolumn{2}{|c}{ Table 2. SLA metrics for PasS } \\
\hline Parameter & Description \\
\hline Integration & $\begin{array}{l}\text { Integration with e- } \\
\text { services and other } \\
\text { platforms }\end{array}$ \\
\hline Scalability & $\begin{array}{l}\text { Degree of use with large } \\
\text { number of online users }\end{array}$ \\
\hline pay as you go billing & $\begin{array}{l}\text { Charging based on } \\
\text { resources or time of } \\
\text { service }\end{array}$ \\
\hline $\begin{array}{l}\text { Environments of } \\
\text { deployment }\end{array}$ & $\begin{array}{l}\text { Supporting offline and } \\
\text { cloud systems }\end{array}$ \\
\hline Servers & Firefox, IExplorer,.. \\
\hline Browsers & $\begin{array}{l}\text { How many developers } \\
\text { can access to the } \\
\text { platform }\end{array}$ \\
\hline Number of developers \\
\hline
\end{tabular}




\section{SLA metrics for SasS:}

Software as a service is an common example for cloud services [8]. If an application is hosted on a cloud platform and infrastructure to provide built-in services for end users of cloud computing. Good examples for SasS are mail, calendar, and social web sites provided by Google, Yahoo, and Microsoft. We present the common metrics parameters for SasS to be an example of metrics in this type of cloud services.

Table 3. SLA metrics for SasS

\begin{tabular}{|l|l|}
\hline Parameter & Description \\
\hline Reliability & $\begin{array}{l}\text { Ability to keep operating } \\
\text { in most cases }\end{array}$ \\
\hline Usability & $\begin{array}{l}\text { Easy built-in user } \\
\text { interfaces }\end{array}$ \\
\hline Scalability & $\begin{array}{l}\text { Using with indivisual or } \\
\text { large orgnizations }\end{array}$ \\
\hline Availability & $\begin{array}{l}\text { Uptime of software for } \\
\text { users in specific time }\end{array}$ \\
\hline Customizability & $\begin{array}{l}\text { Flexible to use with } \\
\text { different type of users }\end{array}$ \\
\hline
\end{tabular}

\section{SLA metrics for Storage as a service:}

Online users use access their data from different geographical locations. In past few years, online storage providers were unable to maintain large size of data because the lack of huge space of storage disks, network performance, and data management systems. Now, data storage service providers like $\mathrm{S} 3$ by amazon.com configure large number of sorage hardware and they are able to manage and serve millions of users in sufficient method of data transferring and managing these data to be compatible with various types of applications. We define parameters for data storage service metrics to be as basic entities for negotiation with storage providers.

Table 4. SLA metrics for Storage as a service

\begin{tabular}{|l|l|}
\hline Parameter & Description \\
\hline Geographic location & $\begin{array}{l}\text { In which availability } \\
\text { zones data are stored }\end{array}$ \\
\hline Scalability & $\begin{array}{l}\text { Ability to increase or } \\
\text { decrease storage space }\end{array}$ \\
\hline Storage space & $\begin{array}{l}\text { How many unit of data } \\
\text { storage }\end{array}$ \\
\hline Storage billing & $\begin{array}{l}\text { How the cost of storage } \\
\text { are calculated }\end{array}$ \\
\hline Security & $\begin{array}{l}\text { Cryptography for storage } \\
\text { and transferring of data, } \\
\text { authentication, and } \\
\text { authorization,... }\end{array}$ \\
\hline Privacy & $\begin{array}{l}\text { How the data will be } \\
\text { stored and transferred }\end{array}$ \\
\hline Backup & $\begin{array}{l}\text { How and where images } \\
\text { of data are stored }\end{array}$ \\
\hline Recovery & $\begin{array}{l}\text { Ability to recover data in } \\
\text { disasters or failures }\end{array}$ \\
\hline System throughput & $\begin{array}{l}\text { Amount of data that can } \\
\text { be retrieved from system } \\
\text { in specific unit of time }\end{array}$ \\
\hline Transferring bandwidth & $\begin{array}{l}\text { The capacity of } \\
\text { communication channels }\end{array}$ \\
\hline $\begin{array}{l}\text { Data life cycle } \\
\text { management }\end{array}$ & $\begin{array}{l}\text { Managing data in data } \\
\text { centres, and use of } \\
\text { network infrastructure }\end{array}$ \\
\hline
\end{tabular}

SLA general terms:

The above section presents the main parameters for metrics in four types of services. Whenever, there are general metrics that can be defined for SLA with any or all types of cloud users. We state the most important parameters as an example to create the basic SLA contract between cloud computing users and providers.

Table 5. SLA general terms

\begin{tabular}{|l|l|}
\hline Term & Description \\
\hline Monitoring & $\begin{array}{l}\text { Who do the monitoring } \\
\text { and what method of } \\
\text { monitoring }\end{array}$ \\
\hline Billing & $\begin{array}{l}\text { Cost of service and how } \\
\text { can be calculated }\end{array}$ \\
\hline Security & $\begin{array}{l}\text { Issues like cryptography, } \\
\text { authentication, and } \\
\text { authorization are main } \\
\text { requirement for cloud } \\
\text { users }\end{array}$ \\
\hline Networking & $\begin{array}{l}\text { How many IPs, } \\
\text { throughput, and load } \\
\text { balancing }\end{array}$ \\
\hline Privacy & $\begin{array}{l}\text { How the data will be } \\
\text { stored and transferred }\end{array}$ \\
\hline Support service & $\begin{array}{l}\text { Cloud providers should } \\
\text { be clear to define the } \\
\text { way for supporting and } \\
\text { helping }\end{array}$ \\
\hline $\begin{array}{l}\text { Local and international } \\
\text { policies }\end{array}$ & $\begin{array}{l}\text { Which policy standards } \\
\text { that providers follow up }\end{array}$ \\
\hline
\end{tabular}

\section{B. Negotiation Strategies}

Negotiation is the method that the service consumer and service provider present their terms and agree or disagree upon the results of this process to reach an agreement acceptable to both sides. There is more than one way of starting the negotiation process in an online environment $[9,10]$. In this section we discuss the scenarios of the negotiation that are possible to be considered for cloud computing. The first scenario is direct negotiation between the cloud consumer and the cloud service provider. In this case, the service provider may create a unique template and define all SLA criteria such as period of contract, billing, and response time. When the SLA document is ready, cloud consumers can review SLA terms and respond by signing the SLA, renegotiate or terminate the negotiation. Direct negotiation is a common method that is used with most of cloud providers today. The second scenario is negotiation via a trusted agent, agents who have good and long experience as to how to select the cloud provider and define the critical parameters for the SLA. This can be a key factor when business wants to focus on the core business activities. Number of activities can be assigned to external agents to do the negotiation in flexible and reliable steps. They may start with the analysis of business processes and goals and complete the negotiation with monitoring all or some of the SLA parameters. Also, the trusted agent can use other agents to carry out some activities like service discovery and monitoring of performance. The third scenario is using more 
than one agent to do the one type of negotiation. As we mention above, there are four different type of cloud services, IasS, PasS, SasS, and storage as a service. Cloud consumer can sign a contract with four different agents (IasS agent, PasS agent, and SasS) to take the responsibility of defining SLA parameters and complete negotiation process. This type of negotiation can be efficient if cloud consumer requires more than one type of cloud services.

\section{Conclusion and Future work}

The effective service level agreement is the key to ensure a service provider meets the agreed terms of services to the cloud consumer. In cloud computing, cloud consumers with clear definition of SLA parameters and flexible negotiation methods can increase the reliability and trust level of cloud provider, cloud consumer relationship. In this paper, nonfunctional requirements of cloud consumers are presented and based on these requirements, the most important criteria for the SLA are defined in order to help cloud users maintain a reliable protocol for negotiation with cloud service providers. The state of the art of SLA frameworks is discussed. At the end, we present three scenarios that can be applied for the cloud computing environment when consumers need to negotiate with cloud providers. As future work, we will design SLA metrics and implement a simulation process to test our framework in the cloud computing environment. The result of this work will be the basic tool that will be used with trust management systems for cloud computing to help consumers select the most reliable service.

\section{REFERENCES}

1.

Armbrust, M., et al., Above the clouds: A berkeley view of cloud computing. EECS Department, University of California, Berkeley, Tech. Rep. UCB/EECS-2009-28, 2009.

2. Amazon. Amazon Elastic Compute Cloud (Amazon EC2). 2008 [cited; Available from: http://aws.amazon.com/ec2.

3. Microsoft. Azure. [cited $201010 \mathrm{March}$ ]; Available from: http://www.microsoft.com/windowsazure/.

4. Google. Google Docs. [cited $201010 \mathrm{March}$ ]; Available from: http://docs.google.com.

5. Andrieux, A., et al. Web services agreement specification (WSAgreement). 2004

6. Keller, A. and H. Ludwig, The WSLA framework: Specifying and monitoring service level agreements for web services. Journal of Network and Systems Management, 2003. 11(1): p. 57-81.

7. Hilley, D., Cloud Computing: A Taxonomy of Platform and Infrastructure-level Offerings. 2009.

8. Muller, J., et al. Customizing Enterprise Software as a Service Applications: Back-End Extension in a Multi-tenancy Environment. 2009: Springer.

9. Pichot, A., et al. Dynamic SLA-negotiation based on WSAgreement. 2008: Citeseer.

10. Rubach, P. and M. Sobolewski, Dynamic SLA Negotiation in Autonomic Federated Environments. 2009. 